\title{
A INTERPRETAÇÃ̃O DAS CORES NA PARATRADUÇÃO DE PARATEXTOS AUDIOVISUAIS - O VERMELHO NA SÉRIE LA CASA DE PAPEL
}

\author{
COLOR INTERPRETATION IN AUDIOVISUAL \\ PARATEXTS TRANSLATION - \\ THE RED IN THE SERIES LA CASA DE PAPEL
}

\section{Morgana Aparecida de Matos ${ }^{*}, * *$}

\section{RESUMO}

A interdisciplinaridade que existe nos Estudos da Tradução permite vislumbrar e consolidar a ideia de paratradução e paratexto audiovisual. Ao saber que os paratextos são essenciais para a tradução e a interpretação, aborda-se aqui, sob os auspícios da paratradução, a relevância dos estudos das imagens apresentadas em tela. A cor vermelha predominante na série televisiva La Casa de Papel, da Netflix, conflui uma imagem subjetiva que corrobora com a compreensão do enredo. Assim, este artigo tem o objetivo de apresentar os caminhos necessários para conformar o estudo das cores - o vermelho especificamente - na paratradução de imagens. A confluência metodológica paratradutiva auxilia na busca de informações, as quais acabam por explicitar os adjetivos que descrevem as sensações do simbolismo da cor, vindouras e perpetuadas na compreensão geral da série que, de forma criativa e aculturada, foram apresentadas nos paratextos audiovisuais estudados.

Palavras-chave: paratradução; paratextos; vermelho; La Casa de Papel.

\section{ABSTRACT}

The interdisciplinarity that exists in Translation Studies allows us to glimpse and consolidate the idea of paratranslation and audiovisual paratext. When knowing that paratexts are essential for translation and interpretation, the relevance of studies of the images presented on screen is addressed here, under the auspices of paratranslation. The predominant red color in Netflix's La Casa de Papel television series converges with a subjective image that corroborates to the plot's understanding. Thus, this article aims to present the necessary paths to conform to the study of colors - specifically red - for translating images. The paratranslational methodological confluence helps in the search for information, which ends up explaining the adjectives that describe the sensations of color symbolism, coming and perpetuating in the general understanding of the series that, in a creative and acculturated way, were presented in the studied audiovisual paratexts.

Keywords: para-translation; paratexts; redi $_{i}$ La Casa de Papel.

\footnotetext{
* Universidade Federal de Santa Catarina, UFSC, Florianópolis, SC, Brasil.morgana_matos@hotmail.com

** Universidad de Vigo, Uvigo. Espanha

Orcid: https://orcid.org/0000-0001-5009-7638
} 


\section{INTROITOS}

A intersecção dos Estudos da Tradução e da Tradução Audiovisual e Midiática é inegável e enfoques múltiplos são necessários para que se tenha em conta a mestiçagem existente no trabalho da pessoa que traduz essa modalidade. Isto porque, a abrangência de público juntamente com a acessibilidade que a tradução aporta aos produtos audiovisuais, traz à tona um campo de infinitas possibilidades de investigação.

Sabe-se que a tecnologia potencializou o progresso das comunicações, fazendo aportar novos comportamentos sociais, que aumentaram a quantidade e a qualidade das informações recebidas pela população. A partir da construção de sistemas, redes, ambientes e cenários destinados ao transporte de informações, a comunicação amplia a midiatização como um processo histórico, que aconteceu de forma expansiva e intensa no século XX. (GÓMEZ DE LA TORRE, 2011)'

Então, a partir de meados do século XX, as mudanças e evoluções naturais da sociedade fizeram emergir comportamentos, ideias, condutas e ideologias que, com a influência da mídia, estabelecem não só a ideia de distanciamento e de uso particular de meios digitais, como também de participação comum. É desta forma que se observa a diversidade cultural na recepção de traduções audiovisuais onde, uma série televisiva produzida na Espanha, por exemplo, com roteiro e atores daquele país, pode ser traduzida para mais de 20 (vinte) idiomas - difundindo o produto, a cultura e os costumes de sua sociedade, inerentes ao produto audiovisual.

Desta forma, o cenário de séries de streaming, como obra a ser traduzida, está alicerçado na acessibilidade a produtos audiovisuais estrangeiros, quando se traduz de uma língua estrangeira a uma língua materna e, ao contrário, oferece transitabilidade quando se traduz de uma língua materna a uma língua estrangeira. A acessibilidade, neste caso, é a capacidade que um programa de televisão, filme, documentário, ou qualquer outro material midiático tem de atingir um público-alvo além do que ele poderia conseguir se estivesse apenas em seu ambiente de base, ou em sua língua base.

A compreensão da conformação dos meios de comunicação é relevante para que se perceba as séries televisivas como obras completas, complexas e, principalmente, como fato gerador de confluências sociais e culturais porque ela interage com a sua audiência. Por isso, se apreende o processo de tradução

1. Para que alguns conceitos sejam mais bem identificados, utiliza-se aqui a acepção do termo "midiatização", conforme Rodrigues (2000, apud SERRA, 2007, p. 10) que o estabelece como um "processo que consiste em tornar acessível a um público mais ou menos vasto e distante uma mensagem sobre um acontecimento ou uma opinião através do recurso a um ou mais media." 
audiovisual como um fazer que implica o emprego de estratégias tradutórias, que levam em conta o significado que emerge da relação existente entre a narrativa visual e a narrativa verbal.

\section{ELO ENTRE TRADUÇAO E IMAGEM}

A multiplicidade das formas de comunicação entre as pessoas torna o processo tradutivo essencial na vida moderna pois, é com a variedade de enunciação e interpretação de significados que se valoriza o ato de traduzir. Tradução é interpretação e está, de acordo com Steiner (2005, p.493), "totalmente implícita na comunicação mais rudimentar»e «explícita na coexistência e no contato de milhares de línguas" vivas no mundo. Portanto, a interpretação alcançada com a tradução vai além do imaginário, abrangendo o real e o histórico através de um conjunto de pensamentos sociais onde se pressupõe que a interpretação se conecta ao coletivo a partir da individualização.

A asserção de que tradução é interpretação ${ }^{2}$, é igualmente abordada por Jakobson (2007) quando ele pontua o significado de um signo linguístico como sua tradução por outro signo que lhe pode ser substituído. A interpretação surge quando Jakobson $(2007$, p. 62) assegura que o signo que substitui o outro pode ser um que o falante escolha como "desenvolvido de modo mais completo". Entendese, portanto, que o "usuário da palavra" interpreta os signos verbais para que sua tradução ocorra. Jakobson (2007), então, desenvolve sua tipologia de tradução, distinguindo três formas de interpretar um signo verbal onde "ele pode ser traduzido em outros signos da mesma língua, em outra língua, ou em outro sistema de símbolos não-verbais". Destaca-se uma delas, qual seja a "tradução intersemiótica ou transmutaçãa" que, conforme o autor, "consiste na interpretação dos signos verbais por meio de sistemas de signos não-verbais" (JAKOBSON, 2007.p. 64).

Neste ínterim, a tradução pode ser um ato de comunicação, uma operação entre textos e um processo mental. A compreensão do que se é traduzido vai além das delimitações linguísticas, de modo que aquele que traduz deve considerar as intenções comunicativas, suas finalidades, as necessidades do destinatário e as características do que é traduzido. Esses fatores estão sujeitos a mudanças e a pessoa

2. A noção de interpretação está vinculada ao ato de interpretar, conforme as acepções do verbo no Dicionário Houaiss da Língua Portuguesa (2009, p. 1099), quando diz: "determinar o significado preciso de (texto, lei, etc.); dar certo sentido a; entender; traduzir ou verter de uma língua para a outra". A ideia, portanto, não abrange a questão específica de "ação tradutória de interpretação", como a que ocorre na língua brasileira de sinais ou em interpretações simultâneas. 
que traduz pode encontrar soluções distintas, em função dos diferentes materiais que serão traduzidos (HURTADO ALBIR, 2001).

A pessoa que traduz, nas palavras de Yuste Frías (2011, p. 258) sempre viveu no mundo da imagem, ao considerar que, mesmo com um texto sem imagem, "o tradutor trabalha com sua capacidade de traduzir imaginários veiculados pelas imagens mentais implícitas no texto'. O autor complementa a ideia afirmando que perto, ao lado, junto de e no texto encontram-se as imagens materializadas nos paratextos icônicos. Ou seja, não se traduz nem se interpreta uma obra se não houver a visão holística do produto finalmente editado, neste caso em tela, que forma parte de todo o conjunto materializado em seus itens paratextuais.

Cada indivíduo, em suas conjecturas pessoais, constrói, através da imagem, seguimentos identificadores de sentido de cada ideia visualizada. Em uma cultura centralizada na imagem, a valorização do que é visto em tela amplia a ratificação do aprofundamento da compreensão da tradução de produtos midiáticos. Os diferentes tipos de telas que estão à disposição - como a televisão, o computador e o celular - expandem a informação ao mostrar comportamentos diferentes e culturas distintas, manifestando a diversidade que há nas sociedades. Nesta era digital emerge a necessidade de um tratamento multidimensional na forma como se faz e se interpreta a tradução.

Há, portanto, uma mescla, uma interdisciplinaridade ao se confrontar tradução, interpretação, imagem, comunicação e tela. A tradução em on para a tela transporta para a Tradução Audiovisual um papel mais específico e profissional quando depara-se com a quantidade de material produtivo que compõem os produtos midiáticos, ampliando seu escopo para Tradução Audiovisual Multimídia. Com isso, a taxonomia tipológica da Tradução Audiovisual amplia-se diariamente e os trabalhos de dublagem, legendagem, localização multimidia, tradução de jogos, por exemplo, alargam-se aos limiares das traduções de livros eletrônicos, de sites, de palestras virtuais, de reuniões e encontros online.

De tal modo, a partir da expressividade linguística, a ideia imagética aparece e as cores são essenciais para se conhecer aspectos imaginários e interpretativos. Atualmente tudo se vê em tela e a tela se tornou o principal ponto de encontro. Muda-se a forma de como se vê e se interpretam essas imagens e sua prospecção está conectada com a forma como as cores são percebidas pelo público. 


\section{PARA-TRADUZIR AS IMAGENS: OS PARATEXTOS AUDIOVISUAIS E A PARATRADUÇÃO}

Sendo um processo entrelaçado de diversidade de informações, a tradução audiovisual pode caracterizar um desafio para quem traduz que é o elo que associa os diferentes meios comunicativos, as diferentes culturas, as diferentes telas e as diferentes imagens. Para tanto, ao correlacionar a linguagem fílmica à Tradução Audiovisual, por exemplo, Chaume (2004) sugere atenção à coesão e coerência no momento tradutório, uma vez que isso pode beneficiar ou não a compreensão do texto pelo receptor. Entende-se que, sem a análise de paratextos e consequentemente sua paratradução, a coerência e a coesão do conteúdo pode se perder e, por isso, ousase ampliar a análise neste artigo à noções paratradutivas, extrapolando o conteúdo interno das séries mencionadas, seguindo o caminho de análise dos Paratextos Audiovisuais e suas imagens através de uma cor predominante, o vermelho.

Atribui-se aos paratextos de textos audiovisuais a característica icônica onde não se é possível traduzir uma unidade verbal sem interpretá-la com a ajuda dos paratextos icônicos editados em tela. Isto é, as unidades icônicas que rodeiam, envolvem, acompanham, prolongam, introduzem e apresentam as unidades verbais são fundamentais para a tradução de produtos de mídia (YUSTE FRÍAS, 2011).

A partir da ideia de paratexto de Genette (2018), observa-se que se pode ampliar seu conceito para os produtos audiovisuais ao se considerar suas aberturas, fechamento e músicas de caracterização, para citar apenas alguns intens. A despeito do construto que envolve a totalidade de uma produção audiovisual, a fim de que o produto seja completo considera-se que a análise de elementos paratextuais é igualmente necessária para a conformação de seu sentido. Para Genette (2018), os paratextos são aqueles elementos que acompanham o texto sendo classificados em peritextos e epitextos, relacionados a textos literários escritos. Matamala (2011), por sua vez, estende a taxonomia de Genette (2018) ao campo dos estudos fílmicos e televisivos. Para a autora, portanto, teasers e trailers podem ser caracterizados como epitextos audiovisuais, e o são.

Os paratextos audiovisuais são, portanto, tudo que prolonga, envolve, alcança e identifica o audiovisual em si. Sem eles o audiovisual não estaria completo, pois ainda conformam a identidade do produto, corroborando com a ideia autoral de perpetuar imagens e características, avocando seu público alvo. Neste caso o público alvo se torna toda e qualquer pessoa que se identifique, inicialmente, com seus paratextos.

Dessa forma, o objetivo é apresentar os caminhos necessários para conformar o estudo do vermelho, cor principal que compõe as imagens de paratextos da série 
La Casa de Papel, onde a mensagem e a formação do imaginário coexistem com a ideia de composição da série e de ênfase na concepção e manutenção de seu público alvo.

Destarte, a análise das cores nos paratextos é feita através da noção de Paratradução que visa analisar o espaço e o tempo de tradução de todo paratexto, com o propósito de asseverar sua existência, sua recepção e seu consumo. Yuste Frías (2011) apregoa que aqueles que traduzem têm consciência de que a concepção e regulação da formação do sentido de qualquer texto são influenciadas pelos seus paratextos, sendo:

[...] em função de um determinado conjunto de unidades verbais, icônicas, entidades iconotextuais ou diferentes produções materiais que, dentro do espaço material do texto, o rodeiam, envolvem ou acompanham (os peritextos) e, fora do espaço material do texto, fazem referência a ele, prolongando-o em outros espaços externos físicos e sociais virtualmente ilimitados (os epitextos). (YUSTE FRÍAS, 2011, p. 260) (tradução nossa) ${ }^{3}$

A materialidade da imagem, na cultura digital, reconhece também a interatividade de seu público alvo, onde qualquer mínimo detalhe visual é percebido e é exigido do tradutor maior qualidade interpretativa, o qual inclui os paratextos icônicos do texto de partida, como menciona Yuste Frías:

Hoje em dia é difícil encontrar um texto em tela onde não apareçam flashes de ícones, cores e imagens fixas ou animadas acompanhando, rodeando e envolvendo o texto a ser traduzido em tela. Todos esses componentes da comunicação visual devem ser lidos e interpretados adequadamente para se traduzir corretamente na era digital. (YUSTE FRÍAS, 2011, p. 258) (tradução nossa) $)^{4}$

Através da Paratradução, em seu nível empírico ou, em seu nível paratradutivo pode-se compreender a utilização das cores nos paratextos das séries analisadas. Sendo a cor, através da imagem, o fundamento deste estudo, o nível empírico traz a oportunidade de ler, compreender, ponderar, interpretar os epitextos, enquanto material além do conteúdo interno da série, formados por vídeos caracterizados como sendo trailers e teasers das séries.

3. No original: [...] en función de un determinado conjunto de unidades verbales, icónicas, entidades iconotextuales o diferentes producciones materiales que, dentro del espacio material del texto, lo rodean, envuelven o acompañan (los peritextos) y, fuera del espacio material del texto, bacen referencia a él prolongándolo en otros espacios externos físicos y sociales virtualmente ilimitados (los epitextos) (YUSTE FRÍAS, 2011, p. 260).

4. No original: Hoy en día resulta difícil encontrar un texto en pantalla donde no aparezcan destellos de iconos, colores e imágenes fijas o animadas acompañando, rodeando y envolviendo en pantalla al texto que se encarga traducir. Todos estos componentes de la comunicación visual deben ser leídos e interpretados adecuadamente para traducir correctamente en la era digital (YUSTE FRÍAS, 2011, p.258). 


\section{O VERMELHO DE LA CASA DE PAPEL NOS PARATEXTOS AUDIOVISUAIS PARA O PÚBLICO BRASILEIRO}

La Casa de Papel (2017) é uma série da empresa de streaming Netflix que trata em seu enredo de um roubo à Casa da Moeda e Selos da Espanha. A narrativa é cheia de mistérios, suspense e cenas de ação. Ao utilizar flasbbacks para submergir na história e fazer conhecer a personalidade de cada um de seus protagonistas e de alguns dos reféns do assalto, valoriza o imaginário através da imagem. Aos poucos seus criadores entrelaçam os telespectadores em uma trama onde há um misto de ansiedade e expectativa por meio da dualidade entre o certo e o errado. Em sua quarta temporada, a série com o passar dos episódios, vai construindo os objetivos de seus personagens principais que, além de buscar o dinheiro, manifestam-se também como rebeldes em relação ao status quo socialmente dominante.

O vermelho é percebido desde as letras tipográficas que identificam a série à imagem principal relacionada ao uniforme dos assaltantes. $\mathrm{O}$ surpreendente é que estes macacões vermelhos também se tornaram as roupas dos reféns o que fez com que, ao longo da trama, as imagens e o reconhecimento dos personagens fossem confundidos.

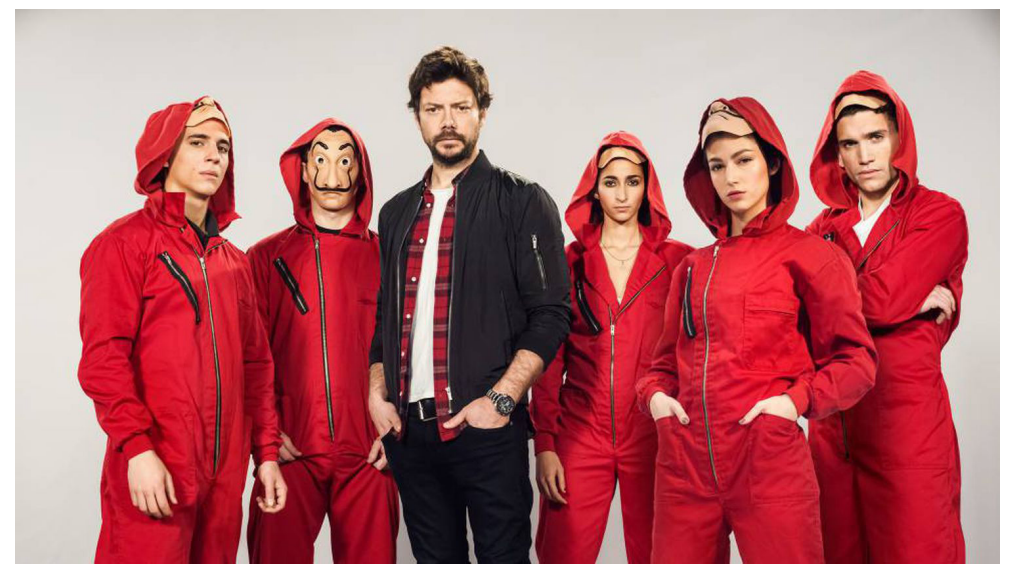

Figura 1. Foto demonstrativa do uniforme utilizado pelos personagens da série La Casa de Papel. Foto ilustrativa de artigo de El País - Brasil, Acessado em: https://brasil.elpais.com/brasil/2018/04/18/cultura/1524042478_371544.html

Acontece que as cores devem ser compreendidas, em seu sentido, através de uma historicidade, de um senso comum e de suas noções simbólicas. Para tanto, a compreensão de o que vem a ser um símbolo, que é diferente de um signo, conforme 
Chevalier e Gheerbrant (1995), passa pela necessidade de interpretação, uma vez que ele está carregado de afetividade e dinamismo, ligado à representação e situado no plano da imagem e do imaginário.

[...] o símbolo supõe uma ruptura do plano, uma descontinuidade, uma passagem a outra ordem i introduz uma nova ordem com múltiplas dimensões. Complexos, indeterminados, mas dirigidos a um certo sentido, os símbolos são também chamados de sintemas ou imagens axiomáticas. (CHEVALIER, GHEERBRANT, 1995, p. 20) (tradução nossa) ${ }^{5}$

Desta forma, segundo Chevalier, que assina a introdução do Diccionário de los Símbolos (1995), o conjunto das relações e das interpretações correspondentes a um símbolo, assim como o conjunto dos símbolos característicos em uma tradição, corresponde ao que vem a ser simbologia. Simbologia pode aparecer ainda como a arte de interpretar os símbolos por análise psicológica, por etnologia comparada, por todos os processos e técnicas de compreensão que constituem a verdadeira hermenêutica do símbolo. Ou seja, a imagem simbólica é o centro ao redor do qual gravita todo o psiquismo que ela põe em movimento (CHEVALIER, GHEERBRANT, 1995, p. 21). Ao aplicar essa conceitualização a este estudo, a simbologia das cores é a que estabelece um conjunto de regras e códigos semióticos que determinam o seu funcionamento e sua compreensão em uma cultura específica.

Por outro lado, as cores são símbolos representativos de diversos elementos, em qualquer cultura e o simbolismo é a capacidade que tem a cor de atuar como um símbolo.

O termo também é usado para designar a capacidade de uma imagem ou uma realidade de servir como um símbolo, por exemplo, o simbolismo da lua, se distingue da simbologia, já mencionada, em que inclui o conjunto das relações e interpretações simbólicas sugeridas pela lua, enquanto o simbolismo se concentra apenas em uma propriedade da lua como possível fundamento dos símbolos. O mesmo, se falamos sobre símbolo hindu, cristão ou muçulmano, não será tanto para designar o conjunto de símbolos inspirados por essas religiões, mas sim a concepção geral que elas fazem do símbolo e de seu uso. (CHEVALIER, GHEERBRANT, 1995, p. 20) (tradução nossa) ${ }^{6}$

5. No original: [...] el símbolo supone una ruptura del plano, una discontinuidad, un pasaje a otro orden, introduce un orden nuevo con múltiples dimensiones. Complejos, indeterminados, pero dirigidos en un cierto sentido, los símbolos son también llamados sintemas o imágenes axiomáticas. (CHEVALIER, GHEERBRANT, 1995, p. 20)

$\mathrm{Na}$ tradução, se manteve o termo "sintemas", traduzido ao espanhol do original em Francês.

6. No original: El término se emplea igualmente para designar la capacidad de una imagen o una realidad para servir de símbolo, por ejemplo, el simbolismo de la luna, se distingue de la simbólica, ya mencionada, en que ésta comprende el conjunto de las relaciones e interpretaciones simbólicas sugeridas de becho por la luna, mientras que el simbolismo no enfoca más que una propiedad general de la luna como fundamento posible de los símbolos. Lo mismo, si bablamos de símbolo bindú, crístiano o musulmán, será no tanto para designar el conjunto de los símbolos inspirados por esas religiones, sino más bien la concepción general que ellas se hacen del símbolo y de su uso (CHEVALIER, GHEERBRANT, 1995, p. 21) 
Estas aclarações terminológicas se fazem precisas quando se quer identificar a originalidade e a riqueza imagética das cores enquanto representações de imagens e apoios para axiomas simbólicos. O simbolismo das cores é evidenciado no Diccionario de los Símbolos dessa forma:

2. O primeiro caráter do simbolismo das cores é sua universalidade, não somente geográfica, como também a todos os níveis do ser e do conhecimento, cosmológico, psicológico, místico, etc. As interpretações podem variar e o vermelho, por exemplo, receber diversas significações segundo as áreas culturais; as cores seguem sendo, não obstante, sempre e em todas as partes, suportes do pensamento simbólico. (CHEVALIER, GHEERBRANT, 1995, p. 317) (tradução nossa $)^{7}$

A questão é: se há uma universalidade no simbolismo das cores, este simbolismo constrói o mesmo imaginário? A possibilidade de que este simbolismo seja múltiplo e interdisciplinar transparece na própria citação de Chevalier e Gheerbrant (1995) onde deixam claro a influência cultural na conformação de sentido das cores.

O vermelho, segundo Chevalier e Gheerbrant (1995), simboliza para muitos povos a primeira das cores por estar ligada à vida, destacando a existência de dois vermelhos: o noturno, feminino, centrípeto, que possui uma atração; e o vermelho diurno, masculino, centrífugo, potente e iluminado como o sol.

O juízo que a imagem do vermelho passa é amplo e ao mesmo tempo direcionado. De acordo com Pastoureau (2013), falar da cor vermelha é quase um pleonasmo pois é a cor por excelência, a primeira de todas as cores. No seu Diccionário de los Colores, Pastoureau (2013) dedica-se ao vermelho em mais de uma acepção: quando fala da cor individualmente e quando a descreve no coletivo como na entrada azul, branco e vermelho. Culturalmente, o autor fala da dicotomia da cor.

Ela obedece a razões culturais que remontam tempos atrás e que se encontram em muitas civilizações. A simbologia do vermelho está quase sempre associada com a do sangue e a do fogo. Por isso existe um vermelho bom e um vermelho mal, ao mesmo tempo que existe um sangue e um fogo que podem ser bons ou maus. (PASTOUREAU, 2013, p.259) (tradução nossa) $)^{8}$

7. No original: El primer carácter del simbolismo de los colores es su universalidad, no solamente geográfica, sino a todos los niveles del ser y del conocimiento, cosmológico, psicológico, místico, etc. Las interpretaciones pueden variar y el rojo, por ejemplo, recibir diversas significaciones según las áreas culturales; los colores siguen siendo, sin embargo, siempre y em todas partes soportes del pensamiento simbólico. (CHEVALIER, GHEERBRANT, 1995, p. 317)

8. No original: Ello obedece a razones culturales que se remontan muy atrás y que se encuentran em muchas civilizaciones. La simbólica del rojo está casi siempre asociada con la de la sangre y el fuego. Por eso bay un rojo bueno y un rojo malo, lo mismo que una sangre y un fuego pueden ser buenos o malos. (PASTOUREAU, 2013, p.259) 
Ao se reportar à utilização do vermelho em La Casa de Papel, o simbolismo da cor apresenta uma universalidade que pode ser constatada nas mais diversas sociedades, mas, especificamente, pode-se verificar seu uso na vida cotidiana e social ocidental. Pastoureau (2013) pontua que o vermelho possui usos e funções distintos. O vermelho como a cor de perigo e de proibição pode ser assinalado na série com a ideia de perigo, que os personagens são assaltantes e ameaçadores, que atuam de forma proibida, fora da lei.

A imagem relacionada à cor vermelha aparece em quase todos os episódios da série, principalmente quando as cenas se concentram nos atos dos personagens no tempo presente, isto é, enquanto atuam efetivamente no assalto à Casa da Moeda. Como pontua Pastoureau (2013, p. 262), o vermelho é a "cor da matéria e do materialismo: presença do vermelho, forte, perto, pesado. O vermelho está aqui e está longe. Materialismo, comunismo. Vermelhos políticos". Sob este aspecto, o simbolismo da cor relaciona-se com a busca dos personagens pelo dinheiro materialismo, indicando a forte presença da cor. Ao assistir a série, compreende-se o seu intento de revolver o status quo social, como já mencionado, indicando as ideias revolucionárias sempre presentes mas gradativamente aumentadas na sequencias das temporadas. O vermelho aparece com um tom político, desafiador, como uma marca registrada de um grupo específico e arrojado.

Deste modo, a presença e a escolha do vermelho como mote imagético central da série possibilita algumas interpretações. Isto porque, ao paratraduzir o peritexto icônico, a delimitação de um objeto de estudo baliza questionamentos referentes aos possíveis procedimentos de tratamento desse objeto. Um fator preponderante é a análise e a observação cultural. Toury (2004) comenta que a tradução é condicionada à cultura receptora, por conta disso, forma parte da cultura meta refletindo as suas relações, independentemente da função ou da identidade da tradução.

Segundo Toury (2004), a determinação da influência cultural, interfere diretamente na tradução, fazendo com que ela chegue a transmutar-se a um papel como o de um texto de origem, justamente por abranger os interesses intrínsecos de seus receptores, de sua cultura meta. A paratradução de um paratexto audiovisual pode ser percebida dessa forma pois, pode dar a sensação de que os atores envolvidos estão falando a língua da cultura meta.

Para tanto, relacionar a imagem e a presença do vermelho na tradução e paratradução de La Casa de Papel serve também como elo de criação do imaginário. O vínculo que há entre todos os aspectos de um audiovisual deve ser analisado e conectado para que a caracterização da obra seja muito bem recebida na cultura 
meta. Assim, as interpretações podem variar e o vermelho, neste caso, pode receber significações distintas. Mesmo havendo denominadores comuns entre as culturas espanholas e brasileiras, a universalidade da cor pode ser extrapolada.

\section{ANÁLISE DOS PARATEXTOS}

O vermelho está presente nos dois paratextos ${ }^{9}$ de La Casa de Papel analisados. Esses paratextos, direcionados ao público brasileiro, são componentes de campanhas publicitárias e de divulgação da série, disponíveis na rede social de vídeos Youtube onde, em geral, os lançamentos desses tipos de vídeos são realizados. Dois dos vídeos fazem parte de uma conta específica da Netflix Brasil, denominada lista de reprodução Netflix da Zoeira, composta por paratextos de séries e filmes, que se apresentam em tons geralmente cômicos.

No vídeo intitulado Bruno Gagliasso faz parte deste elenco com Pedro Alonso, o ator brasileiro mencionado faz um teste para ingressar na série. Para tanto, veste-se de macacão vermelho conforme os personagens de La Casa de Papel. Verifica-se que a ideia principal deste vídeo, elaborado visualmente e verbalmente de forma cômica, era divulgar a contratação do ator pela Netflix e, ao mesmo tempo, promover a série. Vê-se o vermelho como referência, como composição de uniforme de trabalho, com ares alegres e irreverentes no comportamento do ator/personagem.

O ator brasileiro contracena com o ator espanhol Pedro Alonso, que é o personagem Berlim da série. Observa-se que o ator espanhol não está com o traje vermelho, enquanto que Bruno Gagliasso, devidamente trajado e demonstrando sua vontade em entrar para a série, passa por um teste de elenco. Durante o vídeo há marcas culturais linguísticas, onde o ator brasileiro utiliza gírias, expressões e referências da cultura local. Faz referência, por exemplo, às telenovelas brasileiras, onde ele atuou durante muito tempo e, de forma cômica, avisa que não quer fazer "novelas" na Netflix. Outro destaque foi sua menção à uma telenovela infantil mexicana, na qual ele participou da versão brasileira, que foi muito popular no país. No entanto, deve-se enfatizar também que seu «teste»para ingressar na Netflix foi composto de uma cena onde ele deveria retirar a máscara do Salvador Dali, que compõe a roupa dos personagens juntamente com o macacão vermelho.

9. Link da internet para os vídeos analisados, disponíveis no Youtube:

a. Bruno Gagliasso faz parte deste elenco com Pedro Alonso :https://youtu.be/nb6Q1MygDHg

b. Whindersson Nunes também quer La Casa de Papel pra ontem: https://youtu.be/MKs2-qTOc70 


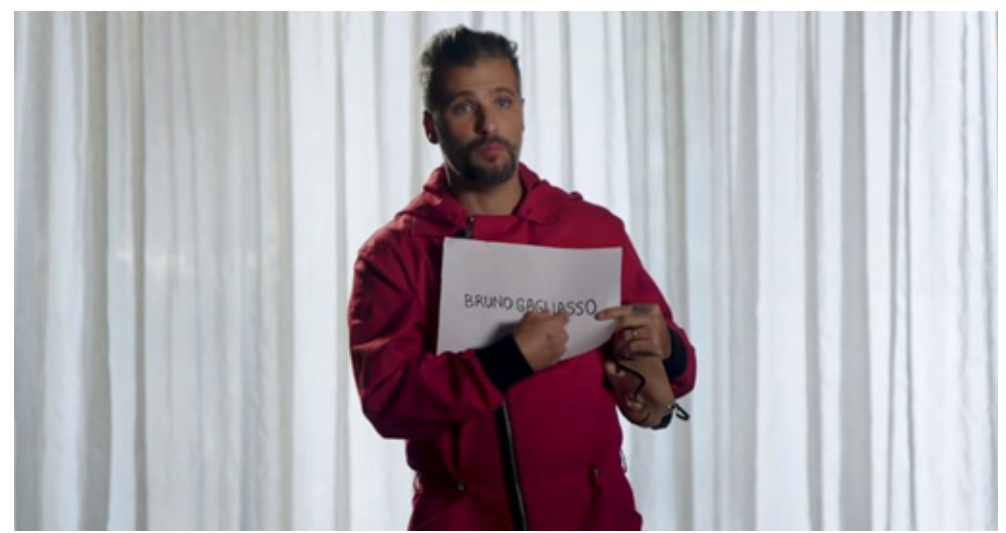

Figura 2. Bruno Gagliasso faz parte deste elenco com Pedro Alonso. Autor desconhecido. Foto acessada pela internet e licenciada sob CC BY-NC-ND

O simbolismo do vermelho neste paratexto reúne funções e significados diferenciados daqueles já mencionados que possuem relação direta com o sentido compreendido na série. Por um lado, ao utilizar o macacão vermelho, o ator brasileiro, além de reforçar a imagem "de seriedade" da série, indica a vontade de pertencer a um grupo ao ser entrevistado pelo ator que representa um dos personagens mais contundentes e antagônicos da obra. Aqui o vermelho forte concebe a atração e desperta dinamismo (PASTOUREAU, 2013). Por outra parte, o peritexto audiovisual paratraduz a imagem de criatividade, de paixão e perigo, de sedução, de alegria e festa - Bruno Gagliasso trata comicamente de um episódio que ocorreu em sua vida particular, relacionado a festas e sua vida sexual. A cor vermelha foi paratraduzida neste vídeo, rementendo seu simbolismo às acepções culturais aceitas e compreendidas pela sociedade brasileira.

O mesmo ocorre com o artista Whindersson Nunes, no vídeo Whindersson Nunes também quer La Casa de Papel pra ontem, onde o comediante, além de interagir com outros atores da série, utiliza a vestimenta vermelha, em um ambiente mais escuro que ressalta a cor e a ideia de irreverência. Ao contrário do Bruno Gagliasso, neste enredo Whinderson Nunes se sente parte do elenco da série pois, recebe os atores espanhóis que não estão «uniformizados», com um novo plano de assalto, desenhado em uma lousa. Este vídeo foi veiculado 4 (quatro) dias antes do lançamento da $4^{\mathrm{a}}$ temporada, justamente para chamar a atenção do público brasileiro. A identidade cultural neste caso está implícita e paratraduzida na fala do ator, que usa palavrões e trocadilhos; no seu gestual, mostrando que se sente parte do elenco, ao usar 
o macacão vermelho e por já ser um ator contratado da Netflix - todos fatores conhecidos dos telespectadores do Brasil.

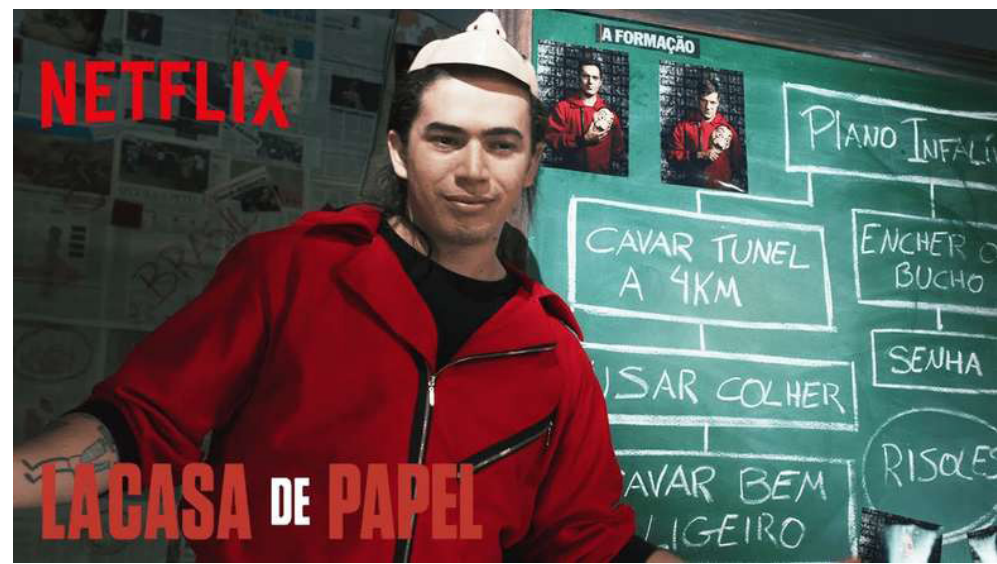

Figura 3. Whindersson Nunes também quer La Casa de Papel pra ontem.

Screenshot da tela do vídeo feito pela autora.

Logo no início do vídeo, Whindersson Nunes atua de forma séria e contida, fazendo as vezes do personagem "Professor", que é o chefe e mentor do grupo de assaltantes. Novamente o vermelho é utilizado como o simbolismo de grupo, de união. A comicidade aparece nos minutos iniciais seguintes quando o ator se cognomina como "Piauí", fazendo referência ao seu estado natal e, da mesma forma, inserindo-se no grupo cujos cognomes eram todos relativos a cidades de diferentes partes do globo. Acontece que Piauí é um estado brasileiro e não uma cidade e esta referência aproxima de forma cômica a série com seus receptores brasileiros.

Este paratexto paratraduzido conjuga o código verbal com o código visual onde o vermelho também simboliza a criatividade, o dinamismo, a alegria e a marca essencial do grupo de personagens de La Casa de Papel.

\section{CONCLUSÕES}

La Casa de Papel é uma série de sucesso devido à sua produção, roteiro, direção, tradução e paratradução. Mesmo que o significado de sucesso seja repleto de concepções imagéticas, o que se vê aqui é uma consequência positiva, onde o êxito é expresso pela popularidade da obra. A captação de público através de vídeos veiculados em rede faz com que sua história se aproxime de seu telespectador. 
Com a Paratradução foi possível ler, compreender, ponderar e interpretar as imagens e o simbolismo da cor vermelha. Os trailers e teasers que formam os paratextos de La Casa de Papel foram paratraduzidos criativamente, onde a formação do sentido remete o paratexto ao seu texto audiovisual. A Netflix desempenha um papel muito íntimo com seus clientes por oferecer esses espetáculos à parte, que são os trailers $e$ teasers. Ao utilizar artistas conhecidos do público brasileiro, a produtora aproxima e vincula o telespectador à série original espanhola, expandindo seu mercado.

Nos vídeos analisados, a presença do vermelho foi fundamental para a composição da história e dos personagens. Ao recompilar a ideia da série em seus paratextos, de forma cômica e criativa, a paratradução transportou ao Brasil os simbolismos expressos com a cor. Isso possibilitou a formação de sentido, conectando diretamente o produto ao seu paratexto e trazendo acessibilidade a um público diferente daquele onde a série foi produzida.

Assim, com o vermelho foi possível estabelecer seguimentos identificadores das ideias do enredo. O vermelho é a imagem principal e através dele a identificação do produto é imediata. Ou seja, as possibilidades de interpretação da imagem, através da cor enfatizam, para os telespectadores brasileiros, o simbolismo da força, da persistência, da coragem contida na obra central. Com os paratextos, acrescentase a diversão, a sensualidade, a ideia de pertencimento, a irreverência e a criatividade. O vermelho, além de toda sua historicidade social e interpessoal, aparece como adjetivo, corroborando com os matizes e as nuances visuais de culturalidade, conformação e interpretação que surgem através dos feitos paratradutivos.

As investigações sobre a influência das cores na Paratradução e sua relação com paratextos audiovisuais ainda necessitam percorrer um longo caminho. A concepção deste artigo buscou traçar alguns primeiros passos necessários para conformar o estudo das cores na paratradução de imagens. Da mesma forma não se esgota aqui as inúmeras possibilidades de pesquisas relativas à cor vermelha, sua simbologia e seu simbolismo. Por meio de uma análise de um produto midiático, que incita contemporaneidade e frescor aos estudos da tradução, constatou-se que a construção de um imaginário é composta por muitos fatores, e um dos principais tem correlação com as cores utilizadas em tela.

\section{REFERÊNCIAS}

CHAUME, F. (2004). Film Studies and Translation Studies: Two Disciplines at Stake in Audiovisual Translation. Meta: Journal des traducteurs, [s.1.], v. 49, n. 1, p.12-24, 01 abr. 2004. Consortium Erudit. 
CHEVAliER, J. M., \& GHEERBRAU, A. (1995). Diccionario de los simbolos. trad. Manuel Silvar e Arturo Rodríguez. Barcelona: Libergraf.

GENETTE, G. (2018). Paratextos Editoriais. Cotia, SP: Ateliê Editorial, 2018. 2a . Ed. Tradução de Álvaro Faleiros.

GÓMEZ DE LA TORRE, A. E. M. (2011). Produtos midiáticos, estratégias, recepção: A perspectiva transmetodológica. C-Legenda - Revista do Programa de Pós-graduação em Cinema e Audiovisual, [S.1.], n. 09, jan. 2011. ISSN 1519-0617.

HURTADO ALBIR, A. (2001). Traducción y Traductología: Introducción a la Traductología. Madrid: Cátedra.

JAKOBSON, R. (2007). Aspectos Linguísticos da Tradução. In: JAKOBSON, Roman. Linguística e Comunicação. Tradução de Izidoro Blikstein e José Paulo Paes. São Paulo: Cultrix.

MATAMALA, A. (2011). Dealing with Paratextual Elements in Dubbing: A Pioneering Perspective from Catalonia. Meta, 56 (4), 915-927, 2011.

PASTOUREAU, M. (2013). Diccionario de los colores. Tradução de Núria Petit Fontserè. Barcelona: Espasa Libros.

SERRA, J. P. (2007). Manual de teoria da comunicação. Covilhã: Livros Labcom.

STEINER, G. (2005). Depois de Babel: questões de linguagem e tradução. Tradução de Carlos Alberto Faraco. Curitiba: UFPR.

TOURY, G. (2004). Las traducciones como hechos de la cultura 'meta': Cómo llegar a las implicaciones metodológicas a partir de una suposición. In: TOURY, Gideon. Los estudios descriptivos de la traducción y más allá: Metodología de la investigación en Estudios de traducción. Madrid: Cátedra.

YUSTE FRIAS, J. (2011). Leer e interpretar la imagen para traducir. Trabalhos em Linguística Aplicada, Campinas, v. 50, n. 2, p. 257-280, Dec. 2011.

Recebido: 18/6/2020

Aceito: 21/7/2020

Publicado: 24/7/2020 